\title{
ON CLIMATE CHANGE ALARMISM IN TOURISM
}

\begin{abstract}
Amir Shani ${ }^{1}$
Abstract: A state-of-the-art scientific evidence is provided that supports the need of tourism scholars to adopt a critical approach when evaluating the various aspects of climate change. The extent of uncertainties regarding the subject matter does not allow those who study climate change and tourism to dismiss substantial doubts and counterevidence with the usual response about "consensus" or "climate deniers." Human-induced climate change is a phenomenon not yet well understood, and thus advocating greenhouse gas mitigation strategies for the tourism industry is precipitous and likely to inflict enormous costs and involve serious pitfalls.
\end{abstract}

Key words: Climate change, Global warming, Skepticism.

\section{INTRODUCTION}

Climate science is not settled. True, the scientific community accepts that the concentration of man-made greenhouse gases could affect the climate, but despite the vast resources invested, the crucial and complex questions for climate policy remain unanswered. Somewhat surprisingly, in their essay "on climate change skepticism and denial in tourism", Hall et al. (2015) seem to agree with that premise, stating that "(t)here is substantial debate over many aspects of climate change science, not only with respect to levels of confidence and uncertainty, but also paradigms and frameworks within which it is understood as a problem to be managed and solved...there is substantial contestation over issues of adaptation, mitigation, vulnerability, and resilience" (p. 17).

These open questions are by no means minor issues but rather substantial deficiencies in the current state of knowledge (Shani \& Arad, 2014). Despite these uncertainties, tourism researchers can be found advocating far-reaching steps for the tourism industry to substantively reduce its greenhouse gas footprint (e.g., Gössling, 2009; McKercher et al., 2010; Müller \& Weber, 2008; Simpson et al. 2008). It is argued here that these and many other environmental-policy suggestions are ill-timed, are of limited practicality, and may even have a negative impact on the tourism industry. Instead, a scientifically-based, skeptical and cautious approach in studies on climate change and tourism is advocated, one that recognizes the complexities and doubts that are the reality of climate change science.

In a response to a previous paper on the subject matter (Shani \& Arad, 2014), Hall et al. (2014) issued a harsh response, which is characterized with all the familiar demagogic tactics of climate change alarmists ${ }^{1}$, including labeling the authors as "climate change deniers," referring to "inconvenient" studies as "outliers," misrepresenting arguments as well as resorting to ad hominem attacks. Shani \& Arad (2015) issued a response addressing most of the concerns raised Hall et al. (2014, 2015). The purpose of the current commentary is to reply to some of the more fundamental arguments mentioned by climate change alarmists such as Hall et al.

\footnotetext{
${ }^{1}$ Senior Lecturer, Department of Hotel and Tourism Management, Ben-Gurion University of the Negev, Beer-Sheva, Israel.
} 


\section{CURRENT CLIMATE MODELS ARE UNRELIABLE}

Hall et al. (2015) argued that climate models, which are relied on by the Intergovernmental Panel on Climate Change (IPCC), "have improved considerably since they were first developed and are well validated" (p. 7), yet provide no evidence to back this claim, apart from quoting the IPCC's statements in its own reports. Indeed, the models have consistently predicted more warming than what has actually been recorded, and have failed to indicate the temperature stability that has been observed over the past 18 years (Beenstock, Reingerwetz \& Paldor, 2014; Curry, 2014). This is significant as since 1990 atmospheric carbon dioxide have risen 13\% (McKitrick, 2014). Hall et al. (2015) reluctantly recognized this evidence, but attribute it to natural internal variability, citing the IPCC's statement that "more that $90 \%$ of the net energy increase in the climate system is stored in the oceans" (p. 8).

However, climate models that have hitherto failed to effectively account for natural influences and variability are clearly deficient in serving as a reliable basis for public policy decisions, including those that are tourism oriented. Recent studies also indicate that the climate sensitivity (i.e. the amount of global surface warming that doubling the concentration carbon dioxide in the atmosphere would eventually produce) is significantly lower than that estimated in the IPCC's latest report (Aldrin, 2012; Lewis \& Curry, 2014; Otto et al., 2013; Skeie et al., 2014). Such evidence implies that humanity has more time to diminish greenhouse gas emissions than argued in the IPCC's reports as well as more time to improve climate projections and provide more accurate information to policymakers.

Moreover, a recent NASA study refutes the controversial suggestion mentioned by Hall et al. (2015), namely that the deep ocean plays a crucial role in heat uptake. Analyzing satellite and direct ocean temperature data from 2005 to 2013, Llovel et al. (2014) found that the earth's ocean abyss below 2,000 meters has not measurably warmed, while the rise in the temperature of the upper oceans - above 2,000 meters - cannot account for the pause in global surface warming. This and other unforeseen evidence (e.g. the significant continuing growth and thickness of Antarctic sea ice, see Williams et al., 2014) demonstrate the severe limits of climate models. Consequently, "(i)t seems too hasty and irresponsible to recommend that the tourism industry take drastic and expensive courses of action that are based on climate forecasting models that have demonstrated very limited success" (Shani \& Arad, 2014, p. 83).

\section{RECENT WARMTH IS NOT ANOMALOUS}

Despite Hall et al.'s claims, recent studies (Gennaretti et al., 2014) did provide strong evidence "for substantial warmth during Roman and Medieval times, larger in extent and longer in duration than $20^{\text {th }}$ century warmth" (Esper et al., 2012, p. 1). These are essential discoveries since the infamous "hockey stick" ${ }^{2}$ studies (e.g., Mann, Bradely \& Hughes, 1998), which were designed to demonstrate that temperatures in the late $20^{\text {th }}$ century were exceptional compared to previous centuries, have been extremely influential in the climate change discourse and used to illustrate that anthropogenic global warming (AGW) is growing and poses a serious problem (McIntyre \& McKittrick, 2003; Soon \& Baliunas, 2003).

The indication that the past decades were not the warmest in the past millennium does not disprove the AGW theory on its own, but indicates that human influences on the global climate are far smaller than natural variations. This "smallness" can perhaps explain why 
climate models have thus far failed to project human influences on climate change. Indeed, despite the assertion made by Hall et al. (2015) that our contemporary period can be referred to as the "Anthropocene," Gibbard \& Walker (2013) argued that it is uncertain whether anthropogenic effects on the climate are "sufficiently distinct, consistent and dated for the proposal of Holocene/Anthropocene boundary to be substantiated" (p. 29). The "Hockey Stick" repudiation also demonstrates the contribution of rational skepticism notwithstanding well-accepted scientific paradigms, even in the face of delegitimization and personal attacks commonly used in climate debates.

\section{ASSESSMENTS OF CLIMATE CHANGE IMPACTS ARE UNSETTLED}

The likely effects of climate change are varied and include both positive and negative outcomes. Up to now, climate change has improved human and planetary welfare (Tol, 2013), and Tol $(2009,2013)$ calculated that climate change would be beneficial overall up to a $2.2^{\circ} \mathrm{C}$ increase in warming from 2009 (i.e. $\sim 3^{\circ} \mathrm{C}$ since the pre-industrial era). In light of the aforementioned recent low climate sensitivity estimates, this provides humanity much more time to adapt to changed temperatures and decarbonize its energy production technologies affordably than is assessed by the IPCC. This, of course, also sheds doubts on the assertion made by Hall et al. (2015) regarding the "urgency to reduce emissions" in the tourism industry.

As evidence to the accumulation of heat in the oceans, Hall et al. (2015) cited the IPCC declaration regarding the rise in global mean sea level. Nevertheless, Rohling et al. (2014) reconstruct sea levels over the past 5.3 million years and show that the current rise in sea level is by no means unprecedented or different from prior interglacial periods (see also Stevens et al., 2014). Additionally, the IPCC oceanographic methodology and views have been criticized for relying on computer modeling rather than on observational facts (Mörner, 2010, 2014). Based on extensive observational studies, Mörner (2013) stated that there "is a very strong argument against the IPCC postulate of an ongoing rapid rise in sea level, and specifically against the proposed acceleration during the last decades" (p. 525) and that the IPCC claims "cannot be validated by observational facts" (p. 528).

Due to uncertainties regarding the social costs of greenhouse gases, more accurate scientific information is required before advocating hasty policies that are detrimental to economic growth, as the necessary technological advances for affordable stabilization of atmospheric carbon dioxide are still missing (Galiana \& Green, 2009; Pielke, Wigley \& Green, 2008). Impact assessments of current climate change have also been criticized for not suitably accounting for substantial future improvements in adaptive capacity, which will advance the capability of coping with climate change. As noted by Goklany (2007a), "(f)uture generations will not only be better off, they should also have at their disposal better and more effective technologies and greater human capital to address not just climate change but any other sources of adversity" (p. 1043).

\section{WEALTHIER IS HEALTHIER}

Hall et al. (2015) correctly stated that "climate change is real" (climate is naturally volatile and has indeed always been dynamic) and "(t)he issue now is how to best respond over the short and long terms" (p. 18). Contrary to the confusion, inaccuracies and uncertainties surrounding the effects of future climate change, data clearly demonstrates that despite (or due to) the rise in carbon dioxide emissions and increase in global surface temperatures 
over the past century, climate has become more - not less - livable for humanity (Goklany, 2007b, 2009). For example, from 2004-2013, worldwide climate-related deaths plummeted by $88.6 \%$ compared to $1930-1939$. Epstein (2014) concludes that the fossil-fuel economy dramatically improves civilization's resilience to adverse climate impacts such as extreme weather events, extreme temperatures, droughts, floods and wildfires (see also Goklany 2011; Ridley 2010). Therefore, "(h)istory provides us ample evidence that 'wealthier is healthier,' since as societies become more affluent their capacity to adapt to changing environmental conditions is significantly improved" (Shani \& Arad, 2015, p. 350).

\section{CONCLUDING REMARKS}

In order to provide "the balance that is missing from the overly alarmist studies on climate change and tourism" (Shani \& Arad, 2014a, p. 82), the reviews of Shani \& Arad (2014, 2015), as well as the current paper, present prominent studies that express skepticism regarding the mainstream assessments of climate change and its consequences. Questioning essential elements of the AGW theory (which is still a scientific theory, regardless of the extent of body of evidence that supports it) is not a "denial" by any means. Acknowledging counterevidence and scientific disputes is a responsibility - not an act of "denial" - of those who study climate change and tourism.

Hall et al. (2015), like other climate change alarmists, declare that they wish "to improve the quality of climate change knowledge and its communication," (p. 6) but at the same time frame the climate change discourse within arbitrary narrow boundaries of fallacious "consensus" and "settled science." The so-called consensus (see Cook et al., 2013) refers, at best, to a high percentage of scientists who agree that human factors play some role in climate change. However, as was clearly demonstrated, "issues such as the extent and rate of climatechange, the extent of the human factor in causing climate change, the consequences of climate change, and the optimal strategies torespond to climate change are at the heart of the scientific debate" (Shani \& Arad, 2015, p. 349). That being the case, speaking of "consensus" is no more than a distraction designed to silence dissenting voices within the scientific community.

One may ask, in light of Hall et al. (2015) explicit confidence in the validity and implications of the AGW theory, why they chose to refer to the "precautionary principle" as the strategy that needs to be applied in coping with climate change. This principle goes further than refraining from actions that have established risks, which Hall et al. argue is the case with human-induced climate change. It calls for exercising caution even with regards to developments with no verifiable risks. Nevertheless, if climate change science is settled, then the precautionary principle is extraneous, as the supposedly harmful AGW was 'proven' and its implications are obvious. But climate science is not settled, and thus the use of the precautionary principle is indeed very useful for climate change alarmists, as it places the burden of proof on climate change skeptics rather than on the alarmists. We are told to take precautionary action to mitigate climate change, even though the crucial aspects of the latter are still under intense scientific dispute. This is not the result of a rational and sustainable approach. but of quasi-religious bigotry that is disastrous for the very concept of human progress.

Jumping on the climate change bandwagon with popular suggestions to curb the greenhouse gas emissions of the tourism industry (and consequently its economic growth) through coercive measures such as carbon caps, taxes and behavioral change of tourists, is a radical manifestation of the precautionary principle, and is not in line with the current 
state of climate change knowledge. The latter supports our call for a skeptical approach in studies on climate change and tourism. The tourism industry is a crucial engine for global economic development, and consequently to the adaptive capacity of humanity regarding climate change. This conclusion is akin to the evidence that vulnerability to natural hazards is significantly reduced as societies become wealthier (Goklany, 2009; Pielke, 2010). As noted by Shani \& Arad (2015), "(t)he AGW policies advocated by tourism scholars will do little to reduce warming, but instead inflict enormous costs and serious pitfalls, preventing the tourism industry from fulfilling its full economic potential" (p. 350).

The American author and philosopher Ayn Rand recognized the ruinous influences of the radical ecological movement long before contemporary AGW hype. In her essay, "The Anti-Industrial Revolution" (1971/1999), Rand reminded us that "(t)he dinosaur and its fellow-creatures vanished from this earth long before there were any industrialists or any men .... But this did not end life on earth. Contrary to the ecologists, nature does not stand still and does not maintain the kind of "equilibrium" that guarantees the survival of any particular species - least of all the survival of her greatest and most fragile product: man" (p. 276). This is a crucial lesson to remember in the presence of current climate change alarmism, which regretfully has found its way into tourism studies as well.

\section{Notes}

1. Climate alarmism is the excessive/exaggerated alarm about climate change and its consequences; the "deliberate ignorance" regarding counterevidence, and the communication of climate change through inflated language while condemning "dissenting" scientists.

2. The "hockey stick graph" (which was eventually invalidated) "purports to chart global temperatures over the past millennium; a sharp rise at the current end is the 'blade' that makes the otherwise flattish line look like a hockey stick" (Brumfiel, 2006, p.1032).

\section{REFERENCES}

1. Aldrin, M., Holden, M., Guttorp, P., Skeie, R.B., Myhre, G., \& Berntsen, T.K. (2012). Bayesian estimation of climate sensitivity based on a simple climate model fitted to observations of hemispheric temperatures and global ocean heat content. Environmetrics, 23(3), 253-271.

2. Brumfiel, G. (2006). Academy affirms hockey-stick graph. Nature, 441(7097), 1032-1033.

3. Cook, J., Nuccitelli, D., Green, S. A., Richardson, M., Winkler, B., Painting, R., et al (2013). Quantifying the consensus on anthropogenic global warming in the scientific literature. Environmental Research Letters, 8(2), 024024.

4. Curry, J. (2014). Uncertain temperature trend. Nature Geoscience, 7, 83-84.

5. Esper, J., Büntgen, U., Timonen, M., \& Frank, D. C. (2012). Variability and extremes of northern Scandinavian summer temperatures over the past two millennia. Global and Planetary Change, 88, 1-9.

6. Galiana, I., \& Green, C. (2009). Let the global technology race begin. Nature, 462(3), 570-571.

7. Gennaretti, F., Arseneault, D., Nicault, A., Perreault, L., \& Bégin, Y. (2014). Volcano-induced regime shifts in millennial tree-ring chronologies from 
northeastern North America. Proceedings of the National Academy of Sciences, 111(28), 10077-10082.

8. Gibbard, P. L., \& Walker, M. J. C. (2014). The term 'Anthropocene' in the context of formal geological classification. Geological Society, London, Special Publications, 395(1), 29-37.

9. Goklany, I. M. (2007a). Is a richer-but-warmer world better than poorer-but-cooler world? Energy \& Environment, 18(7\&8), 1023-1048.

10. Goklany, I. M. (2007b). The improving state of the world: why we're living longer, healthier, more comfortable lives on a cleaner planet. Washington, DC: Cato Institute.

11. Goklany, I.M. (2009). Deaths and death rates from extreme weather events: 19002008. Journal of American Physicians and Surgeons, 14(4), 102-109.

12. Gössling, S. (2009). Carbon neutral destinations: a conceptual analysis. Journal of Sustainable Tourism, 17(1), 17-37.

13. Hall, C. M., Amelung, B., Cohen, S., Eijgelaar, E., Gössling, S., Higham, J., ... \& Scott, D. (2015). On climate change skepticism and denial in tourism. Journal of Sustainable Tourism, 23(1), 4-25.

14. Lewis, N., \& Curry, J.A. (2014). The implications for climate sensitivity of AR5 forcing and heat uptake estimates. Climate Dynamics, doi:10.1007/s00382-0142342-y.

15. Llovel, W., Willis, J.K., Landerer, F.W., \& Fukumori, I. (2014). Deep-ocean contribution to sea level and energy budget not detectable over the past decade. Nature Climate Change, 4(11), 1031-1035.

16. Mann, M.E., Bradley, R.S., \& Hughes, M.K. (1998). Global-scale temperature patterns and climate forcing over the past six centuries. Nature, 392(6678), 779787.

17. McIntyre, S., \& McKittrick, R. (2003). Corrections to the Mann et al. [1998] proxy database and Northern Hemisphere average temperature series. Energy \& Environment, 14(6), 751-771.

18. McKercher, B., Prideaux, B., Cheung, C., \& Law, R. (2010). Achieving voluntary reductions in the carbon footprint of tourism and climate change. Journal of Sustainable Tourism, 18(3), 297-317.

19. McKitrick, R.R. (2014). HAC-Robust Measurement of the Duration of a Trendless Subsample in a Global Climate Time Series. Open Journal of Statistics, 4(07), 527-535.

20. Mörner, N. A. (2010). Some problems in the reconstruction of mean sea level and its changes with time. Quaternary International, 221(1), 3-8.

21. Mörner, N. A. (2011). Sea level changes in the Indian Ocean: Observational facts. In Proceeding of the Mumbai conference on Climate Change and Shifting Science. http://climatecorruption.com/pdf/Sea\%20levels-Observational\%20Facts\%20\%20Morner\%20Dec11.pdf. Accessed 14 December, 2014

22. Mörner, N. A. (2013). Sea level changes past records and future expectations. Energy \& Environment, 24(3), 509-536.

23. Müller, H., \& Weber, F. (2008). Climate change and tourism e scenario analysis for the Bernese Oberland in 2030. Tourism Review, 63(3), 57-71.

24. Otto, A., Otto, F. E., Boucher, O., Church, J., Hegerl, G., Forster, P. M., ... \& Allen, M. R. (2013). Energy budget constraints on climate response. Nature Geoscience, 6(6), 415-416. 
25. Pielke, R. (2010). The Climate Fix. New York: Basic Books.

26. Pielke, R., Jr., Wigley, T., \& Green, C. (2008). Dangerous assumptions. Nature, 452, 531-532

27. Rand, A. (1999). The Return of the Primitive: The Anti-Industrial Revolution. New York: Meridian. Original work published 1971.

28. Ridley, M. (2010). The Rational Optimist: How Prosperity Evolves. London: Fourth Estate.

29. Rohling, E.J., Foster, G.L., Grant, K.M., Marino, G., Roberts, A. P., Tamisiea, M. E., \& Williams, F. (2014). Sea-level and deep-sea-temperature variability over the past 5.3 million years. Nature, 508(7497), 477-482.

30. Shani, A., \& Arad, B. (2014). Climate change and tourism: Time for environmental skepticism. Tourism Management, 44, 82-85.

31. Shani, A., \& Arad, B. (2015). There is always time for rational skepticism: Reply to Hall et al. Tourism Management, 47, 348-351.

32. Simpson, M. C., Gössling, S., Scott, D., Hall, C. M., \& Gladin, E. (2008). Climate change, adaptation and mitigation in the tourism, sector: Frameworks, tools and practices. Paris, France: UNEP, University of Oxford, UNWTO, WMO.

33. Skeie, R.B., Berntsen, T., Aldrin, M., Holden, M., \& Myhre, G. (2014). A lower and more constrained estimate of climate sensitivity using updated observations and detailed radiative forcing time series. Earth System Dynamics, 5(1), 139-175.

34. Soon, W., \& Baliunas, S. (2003). Proxy climatic and environmental changes of the past 1000 years. Climate Research, 23(2), 89-110.

35. Stevens, T., Jestico, M.J., Evans, G., \& Kirkham, A. (2014). Eustatic control of late Quaternary sea-level change in the Arabian/Persian Gulf. Quaternary Research, 82(1), 175-184.

36. Tol, R.S.J. (2009). The economic effects of climate change. The Journal of Economic Perspectives, 23, 29-51.

37. Tol, R.S.J. (2013). Bootstraps for meta-analysis with an application to the impact of climate change. Working Paper Series 6413, Department of Economics, University of Sussex, September.

38. Tol, R.S.J. (2013). Climate change: the economic impact of climate change in the twentieth and twenty-first centuries. In B. Lomborg (Ed.), How Much Have Global Problems Cost the World? A Scorecard from 1900 to 2050 (pp. 117-130). Cambridge: Cambridge University Press.

39. Williams, G., Maksym, T., Wilkinson, J., Kunz, C., Murphy, C., Kimball, P., \& Singh, H. (2014). Thick and deformed Antarctic sea ice mapped with autonomous underwater vehicles. Nature Geoscience.

http:/www.nature.com/ngeo/journal/vaop/ncurrent/full/ngeo2299.html?cmpid=psc au Accessed 14 December 2014. 